\title{
Competitive Frontiers: Women In Management And The Performance Of Microfinance Banks In South-East Nigeria
}

\author{
Dr. Nonyelum Ugwu Joy \\ Department of Business Administration/Entrepreneurship \\ Federal University, Ndufu-Alike Ikwo, Ebonyi State \\ Dr. Peter Ositadinma Ndubuisi \\ Department of Entrepreneurship Studies \\ Chukwuemeka Odumegwu Ojukwu University, Igbariam, Anambra State \\ Dr. Charles Ogbaekirigwe \\ Department of Business Administration/Entrepreneurship \\ Federal University, Ndufu-Alike Ikwo, Ebonyi State
}

\begin{abstract}
This study focused on Competitive Frontiers: Women in Management. The study took a descriptive survey approach and covered a sample size of 64 members of senior staff randomly selected from Ecobank and First Bank Nig. Plc within the South-Eastern part of Nigeria. A five point likert scale questionnaire was used to collect data and the data collected was analyzed using inferential statistics. The hypotheses were tested using Mann-Whitney Test (U) using the 20.0 version of statistical package for social sciences (SPSS). From the result of the SPSS output for hypotheses 1 and 2, their respective pvalues were lesser than the level of significance (i.e 0.000 and $0.04<0.05$ respectively), this led to the rejection of the two null hypotheses tested in this work. The study therefore recommends that banks should deploy more women in the management of their marketing activities in order to enhance their marketing performance which has a direct link to their competitiveness
\end{abstract}

Keywords: Competitive, Management, Marketing frontier, Operational efficiency

\section{INTRODUCTION}

The strive by organizations for a better market placement has opened vistas or fronts for competition. This is fuelled by innovation in information and communication technology and globalization that are increasingly reducing market distance, crumbling trade barriers across the globe and availing market participants with abundant market information at a reduced cost and at an unimaginable speed. These circumstances has made it possible for increased competition among firms and industries while dragging innovation to open-up new battle fronts of competition. On the other hand, in the administration, leadership and management of organizations, there is a global call for gender inclusiveness i.e ensuring that women are by policy made to participate in the top management of organizations. While this is seen as laudable, the competitive implication of this is seldom discussed, hence; the aptness of this study. Competitive frontiers have occupied the subject of strategic management in most recent times and are of critical importance of considerations relating to the first, being the central hub for measuring the success and the failure of organizations in its decisions and strategic plans. Secondly, the study of performance is facing many challenges, particularly strategic issues. The nature of the different objectives of the parties associated with them requires determining the appropriate metrics that can be used in measuring performance and source-based information in the measurement. How to integrate different measurements to provide a realistic picture of 
the organization's competitive performance represents a strategic perspective or the perspective of the market. The most important measures adopted in competitive performance were done by Nayef (2007). They include;

1. Market gauges and indicators related to growth in shares refer to the company's ability to enter new market segments through growth in sales or increase the number of machines.

2. Value-added measures: This is one of the favorite indicators in measuring the returns achieved by the company. The intervention exists in the context of value-added indicators of innovation, learning and the developing new services, and technical leadership and rates of improvement and innovation.

3. Satisfaction measures: There are two. The first is goods about the case of certain purchase and evaluates their results. The second is the accumulated goods which is based on the total purchases and transactions for clients with the organization. However, this refers to the customer's dealings with the company in the past, present, and future.

4. Location competitive standards: Competitive location for industry refers to its ability to achieve sustainable competitive advantages over its competitors in the market, whatever the source of these competitive advantages is. It does not matter if it is in the ability to adapt and survive or in the rapid growth of the industry environment.

\section{Statement of Problems}

The Nigerian woman works in an environment where there is gender stereotype against them arising from the society's socio-cultural beliefs that tends to confine her role in the society to domestic chores and child bearing. However, over the years, the Nigerian women have aligned with the global trend of gender equity and women emancipation and are therefore advancing their careers in management position of organizations. While this has become empirical, it does appear that organizations tend to exploit their gender weaknesses to advance their course in the competitive world of business. This study is therefore faced with the problem of examining how women in management influences the competitive frontier of organizations

\section{Objectives of Study}

The main objective of this study is to examine competitive frontier: women in management. Its specific objectives include;

i. To examine the influence of women in management on the marketing frontier of banks

ii. To examine the influence of women in management on the operational efficiency frontier of banks

\section{Research Questions}

The following research questions were asked in this study;

i. Do Women in management influence the marketing frontier of banks significantly?

ii. To what extent do women in management influence the operational efficiency frontier of banks?

\section{Hypotheses}

This study is guided by these hypothetical assertions

$\mathbf{H}_{01}$ : Women in management does not influence the marketing frontier of banks

$\mathbf{H}_{\mathbf{0 2}}$ : Women in management does not influence the operational efficiency of banks 


\section{Conceptual Framework \\ Women in Management}

The issues of women and their career have been explored for more than 30 years. Many researchers have begun to develop explanatory theories and concepts to these issues. This study observed that there are three dominant dimensions to the study of women in management as espoused by Evetts (2000), these dimensions include; Cultural dimensions: family and feminine ideologies and cultures, Structural dimensions: family structures and processes and Action dimensions: women's choices and strategies. However, only one dimension which is of most relevance to this study shall be examined

\section{Action Dimensions: Women's Choices and Strategies}

The cultural and structural dimension of explanations focuses primarily on the determinants of careers or at least the constrictions in the careers of women (Hakim, 2006). In general, in the action dimension of explanations, careers are not determined in any casual way by structural and cultural factors. Structural processes and cultural expectation constrain choice but nevertheless women do choose to an extent between opportunities available to them. Careers frequently result from earlier decisions, which narrow the range of opportunities. Careers also result from coincidence, accident and encounters as well as from career planning, structural and organizational changes and changes in cultural conditions (Hakim, 2006).

The 1980s saw the re-emergence of an action or agency frame of reference, however, in the context of cultural and structural constraints, women were perceived as actively building their lives and careers out of the conditions created and maintained by larger structural and cultural forces. Thus, careers are not perceived as determined by cultural and structural forces. Such forces are mediated in their impact by processes of social interaction: cultures and structures are experienced; individuals respond and react in diverse ways; and people construct their own meanings, make choices and develop strategies. In the study of the action dimensions of women's careers, the difficulties of organizational and professional promotion structures and the cultural belief system of family and femininity still have to be managed by women (Wood, 2008).

Women manage such constraints in different ways, which include adaptation, manipulation, negotiation, resistance and confrontation. Tactics for coping with constraints vary between one woman and another and any one woman will vary over time and in different contexts (Hopkins and Bilimoria, 2008). No particular strategy is more important than others especially in maledominated careers, sometimes have received a disproportionate amount of media attention and acclaim. Such women have also received a disproportionate amount of criticism. Most of the time, the criticism comes from feminist researchers who have interpreted successful women's promotion achievements as a sell-out to or an adaptation of male career patterns and values by means of the exploitation of other women's labour (e.g., cleaners and nannies) (Wood, 2008). The action dimension emphasizes the rational choice element of all career decisions in the face of complex career constraints and variable career resources.

To analyze career experiences, the action dimension of careers (of women's careers and career strategies) is considered alongside the cultural and structural determinants of careers in particular organizational contexts. The demonstration of wide variety and diversity, as well as complexity, in the choices that are made and the strategies developed is discussed. Some women are developing direct careers in the industrial or commercial organizations or in schools in the education system. Some are achieving high promotions by remaining (or having to remain) single and/or childfree. Others are developing highly complex caring arrangements and coping strategies at least for a period. Other women are choosing not to focus on 
promotion but instead to balance paid work and family responsibilities either for a short period or as a longer-term career strategy (Hakim, 2006).

Some women choose particular sectors or their organizations and professions perhaps avoiding managerial positions, again for shorter or longer periods, in order to enable them to fulfill other responsibilities (Jogulu and Wood, 2006). Other women choose career patterns with part-time and practitioner careers, again for short or longer periods. Several women, particularly in teaching, take career breaks beyond statutory maternity leave, though younger women and women in engineering, science and banking are perhaps less inclined to do this. Most of these women know that particular career choices assist while others are likely to handicap promotion progress, but they opt for such choices as seeming to meet immediate needs, aims and goals. The consequences for the careers of the engineers and scientists of choosing the professional specialist rather than the managerial route are well recognized. Obviously some of the women would change their minds over the course of their careers and perhaps become unhappy with a particular course of action felt to be the best way at the time of decision. This is what makes careers dynamic a process rather than a once-and-for-all decision. Also, some women have fewer choices to make in their particular organizational contexts or fewer resources in their personal lives. Particular career choices limit future career options and opportunities and careers often result from earlier decisions, which close some doors and narrow the range of future possibilities (O'Neil et al., 2008). It is also important to emphasize that career choice and strategies are essentially personal and individual. Collective action does not form a part of the career decision making process (O'Neil et al., 2008). Women should therefore develop individual and personal solutions to the cultural and structural constraints in their careers; either by prioritizing promotion or by negotiating various balances in their careers. These women are active in constructing resolutions and devising personal strategies. They choose between the examples set by other women in their organizations but they do not expect company or educational policies, trade union procedures or feminists principles to help sort their arrangements. Their personal situations and career ambitions and intentions are perceived as too variable and diverse to be adequately met by corporate systems or collective action.

\section{Types of Women in Management}

Work-Centred Women: this group of women is in a minority, despite the massive influx of women into higher education and into professional and managerial occupations in the last three decades. Work-centred people (men and women) are focused on competitive activities in the public sphere, in careers, sport, policies or the arts. Family life is fitted around their work; many of these women remain childless, even when married. Qualifications and training are obtained as a career investment rather than as an insurance policy, as in the adaptive group. The majority of men are work-centred, compared to only a minority of women, even women in professional occupations. Preference theory predicts that men will still retain their dominance in the labour market, policies and other competitive activities, because only a minority of women is prepared to prioritise their jobs (or other activities in the public sphere) in the same way as men. In the long run, it is work-centred people who are most likely to survive and become high achievers, in greedy occupations.

Adaptive Women: This group of women prefers to combine employment and family work without giving a fixed priority to either. They want to enjoy the best of both worlds. Adaptive women are generally the largest group among women and are in substantial numbers in most occupations. Certain occupations, such as school teaching, are attractive to women because they facilitate a more even work-family balance. The great majority of women who transfer to 
part-time work after they have children are adaptive women, who seek to devote as much time and effort to their family work as to their paid jobs. For example, seasonal jobs, temporary work or school-term-time jobs all offer a better work-family balance than the typical full-time job, especially if commuting is involved. When flexible jobs are not available, adaptive women may take ordinary full-time jobs or else withdraw from paid employment temporarily. Adaptive people are the group interested in schemes offering work-life balance and familyfriendly employment benefits and will gravitate towards careers, occupations and employers offering these advantages.

Home-Centred or Family-Centred Women: This group of women are a minority and relatively invisible in the Western as well as in Asian world, including Thailand, given the current political and media focus on working women and high achievers. Home-centred women prefer to give priority to private life and family life after they marry. They are most inclined to have larger families and these women avoid paid work after marriage unless the family is experiencing financial problems. They do not necessarily invest less in qualifications, because the educational system functions as a marriage market as well as a training institution. Despite the elimination of the sex differential in educational attainment, home-centred women are now marrying a man with substantially better qualifications and the likelihood of marrying a graduate spouse is hugely increased if the women herself has obtained a degree (Hakim, 2000; Blossfeld and Timm, 2003).This may be why women remain less likely to take courses in the arts, humanities or languages, which provide cultural capital but have lower earnings potential. This group of workers is most likely to drop out of greedy careers relatively early in adult life.

In general, it is necessary to differentiate between a person's core values and life goals and the multitude of topics on which public opinion data collected. There is an important theoretical and methodological distinction between personal goals and preferences, which are causal in relation to individual behaviour and general social attitudes and societal norms, which are usually non-causal. There is a distinction between choice and approval, between personal goals and public beliefs, between what is desired by the survey respondent for their own life and what is considered desirable in society in general. The two are not coterminous and there is only a weak link between society norms and personal preferences and goals (Hakim, 2004).

Preference theory also provides a different explanation for the continuing pay gap and occupational segregation. Moreover, it predicts that they will persist in the $21^{\text {st }}$ century and that men will continue to outnumber women in the top jobs, simply because they try much harder to get them. The majority of working women seek a larger degree of work-life balance more than men do. Women are more likely to ask for shorter work hours than to ask for higher pay or promotion (Babcock and Laschever, 2003).

\section{Barriers to Women's Progression in Management}

The core obstacles to the emergence of women in managerial positions include gender role stereotyping and discrimination.

Gender role stereotypes: Gender stereotypes have been defined as categorical beliefs regarding the traits and behavioural characteristics ascribed to individuals based on their gender (Ginige, 2007), or a set of attributes ascribed to a group and believed to characterize its individual members simply because they belong to that group. Prime, Jonsen, Carter, and Maznevski (2008), believe that the influence of these stereotypes can be represented on two important patterns. First, the qualities that people associate with women are totally different from those which people associate with leaders. Second, the qualities which people associate with men are similar to those which they associate with leaders. Men tend to be seen as 
naturally equipped to lead, because of this match between stereotypically masculine attributes and idealized leadership. This tendency has been called think-manager-think-male.

Gender discrimination: Discrimination happens by treating women differently from men and it occurs when people perceive female managers as different from males. This treatment is seen as both logical and rational by people who hold negative stereotypes about women managers. Subtle discrimination may take many shapes; for example, based on the assumption that women prefer family commitments, managers may decide to hand over an important task to a man rather than to a woman. Beliefs about degree of fit are another form of subtle discrimination. Perceptions that women will somehow change the management process by virtue of their gender lead women to be excluded from senior management positions (Owen \& Todor, 1993).

\section{Theoretical Framework}

This paper adopted a broad theoretical perspective to examine the factors that facilitate or block women's advancement in positions. It is suggested that women's career progression in management is affected by individual, organizational and societal factors (Yukongdi and Rowley, 2009). All of these variables simultaneously interact with one another.

Gender Equity Theory: Gender equity and economic structures are closely linked. Gender equity has been promoted by international development organizations (e.g., the World Bank) as a result of economic development and positive associations between low fertility and good health in women and children. Reduced income equality is attributable to: increased wage disparities between high- and low-skilled workers; 'structural adjustment' (i.e. decentralization of publicly funded social services); tax policies favoring the wealthy; and the decline of labour nations (Moss 2002). This indicates that job characteristics (e.g., job strain caused by low control and high demands), limited psychological and social resources, perceived hostility and discrimination, and lifestyle 'incompatibility' determine quality of health more than maintaining employment and financial rewards.

\section{METHODOLOGY}

This study took a descriptive survey approach and covered a sample size 64 members of senior staff randomly selected from Ecobank and First Bank Nig. Plc within the South-East Nigeria, using the balloting technique. Questionnaires from which data for this study was generated was administered physically (face-to-face) on the respondents and the same approach was used in the retrieval of the questionnaires, the data collected was then analyzed using inferential statistics. The hypotheses were tested using Mann-Whitney Test (U) using the 20.0 version of statistical package for social sciences (SPSS). The Mann-Whitney test is expressed mathematically as;

$$
U_{1}=R_{1}-\frac{n_{1}\left(n_{1}+1\right)}{2}
$$

Where $\mathrm{R}_{1}=$ Rank of the sample size, $\mathrm{n}_{1}=$ sample size and $\mathrm{U}=$ Mann-Whitney test Statistic 
Test of Hypotheses

\section{RESULTS AND DISCUSSIONS}

SPSS Output for Hypothesis One

Table 1. Descriptive Statistics

\begin{tabular}{|l|r|r|r|r|r|}
\hline & \multicolumn{1}{|c|}{$\mathrm{N}$} & \multicolumn{1}{c|}{ Mean } & Std. Deviation & \multicolumn{1}{c|}{ Minimum } & Maximum \\
\hline RESPONSE & 20 & 21.8000 & 10.91884 & 3.00 & 40.00 \\
RANKS & 20 & 3.0000 & 1.45095 & 1.00 & 5.00 \\
\hline
\end{tabular}

\section{Mann-Whitney Test}

Table 2. Ranks

\begin{tabular}{|r|l|r|r|r|}
\hline & RANKS & $\mathrm{N}$ & $\begin{array}{c}\text { Mean } \\
\text { Rank }\end{array}$ & $\begin{array}{c}\text { Sum of } \\
\text { Ranks }\end{array}$ \\
\hline \multirow{2}{*}{ RESPONSE } & 1.00 & 4 & 2.50 & 10.00 \\
& 2.00 & 4 & 6.50 & 26.00 \\
& Total & 8 & & \\
\hline
\end{tabular}

Table 3. Test Statistics ${ }^{a}$

\begin{tabular}{|l|r|}
\hline & \multicolumn{1}{|c|}{ RESPONSE } \\
\hline Mann-Whitney U & .000 \\
Wilcoxon W & 10.000 \\
Z & -2.309 \\
Asymp. Sig. (2-tailed) & .021 \\
Exact Sig. [2*(1-tailed & $.012^{\mathrm{b}}$ \\
Sig.)] & \\
\hline
\end{tabular}

a. Grouping Variable:

b. Not corrected for ties.

Discussion: From the test statistic table above, the value for Mann-Whitney (U) is 0.000 which is less than the 0.05 level of significance; hence, the null hypothesis is rejected. This simply implies that women in management has significant influence on the marketing frontier of banks

\section{SPSS Output for Hypothesis Two}

\section{Descriptive Analysis for Research Question II}

Table 4. Descriptive Statistics

\begin{tabular}{|l|r|r|r|r|r|}
\hline & \multicolumn{1}{|c|}{$\mathrm{N}$} & \multicolumn{1}{|c|}{ Mean } & Std. Deviation & Minimum & \multicolumn{1}{c|}{ Maximum } \\
\hline RESPONSE & 20 & 21.8000 & 6.94793 & 10.00 & 33.00 \\
RANKS & 20 & 3.0000 & 1.45095 & 1.00 & 5.00 \\
\hline
\end{tabular}


Table 5. Ranks

\begin{tabular}{|r|r|r|r|r|}
\hline & RANKS & N & \multicolumn{1}{|c|}{ Mean Rank } & Sum of Ranks \\
\hline \multirow{3}{*}{ RESPONSE } & 1.00 & 4 & 2.50 & 10.00 \\
& 2.00 & 4 & 6.50 & 26.00 \\
& Total & 8 & & \\
\hline
\end{tabular}

Table 6. Test Statistics ${ }^{a}$

\begin{tabular}{|l|r|}
\hline & \multicolumn{1}{|c|}{ RESPONSE } \\
\hline Mann-Whitney U & .04 \\
Wilcoxon W & 10.000 \\
Z & -2.337 \\
Asymp. Sig. (2-tailed) & .019 \\
Exact Sig. [2*(1-tailed & $.029 \mathrm{~b}$ \\
Sig.)] & \\
\hline
\end{tabular}

a. Grouping Variable:

b. Not corrected for ties.

Discussion: From the test statistic table above, the value for Mann-Whitney (U) is 0.04 which is less than the 0.05 level of significance; hence, the null hypothesis is hereby rejected. This simply suggests that women in management have influence on the operational efficiency of banks.

\section{FINDING}

This paper discovered that the influence of women in management on competitive frontier is dominant in the marketing dimension when compared with the operational efficiency dimension, hence the result ( 0.000 and 0.04 respectively).

\section{CONCLUSION AND RECOMMENDATIONS}

It was concluded that women in management have significant influence on the competitive frontiers of the banks under study. The study therefore recommended that banks should deploy more women in the management of their marketing activities in order to enhance their marketing performance which has a direct link to their competitiveness.

\section{References}

Babcock, L. \& Laschever, S. (2003). Women Don't Ask: Negotiation and the Gender Divide, Princeton University Press, Princeton, pp. 41-85.

Blossfeld, H-P, and Timm, A. (2003). Who Marries Whom? Educational Systems as Marriage Markets in Modern Societies. Dordrecht, Kluwer Academic

Eagly, A. (2007). Female leadership advantages and disadvantage: Resolving the contradictions. Psychology of Women Quarterly, 31, 1-12.

Evetts, J. (2000). Analysing change in women's careers: Culture, structure and action dimensions. Gender, Work and Organisations, 7(1): 57-67.

Forsyth, D.R., Heiney, M.M. and Wright, S.S. (1997). Biases in appraisals of women leaders', Group Dynamics, vol. 1, no. 1, pp. 98-103.

Ginige, K.N., \& Haigh, R., \& Amaratunga, D. (2007). Gender stereotypes: A barrier for career development of women in construction, Proceedings of the 3rd Annual Built Environment Education Conference of the Centre for Education in the Built Environment, University of Westminster. Retrieved from http://www.cebe.heacademy.ac.uk/news/events/beecon2007/files/P3 K Ginige.pdf

Hakim, C. (2000). work-lifestyle choices in the twenty-first century: preference theory. Routledge: London 
Hakim, C. (2004). Key Issues in Women's Work: Female Diversity and the Polarisation of Women's Employment. London: Glass-House Press.

Hakim, C. (2006). Women, Careers, and Work-life Preferences, British Journal of Guidance \& Counselling, vol. 34, no. 3, pp. 279-294.

Jogulu, U.D. and Wood G. J. (2006). The Role of Leadership Theory in Raising the Profile of Women in Management', Equal Opportunities International, vol. 25, no.4, pp. 236-250.

Moss, N. E. (2002). Gender Equity and Socioeconomic Inequality: a Framework for the Patterning of Women's Health', Social Science \& Medicine, vol. 54, no. 5 pp. 649-661

O' Neil, D. A. and Hopkins M. M. (2008). Women's Careers at the Start of the 21st Century: Patterns and Paradoxes, Journal of Business Ethics, vol. 80, no. 4, pp. 727-743.

Owen, C., \& Todor, W. (1993). Attitudes towards women as managers: still the same. Business Horizons, , 12-16.

Prime, J., Jonsen, K., Carter, N., \& Maznevski, M. (2008). Managers' perceptions of women and men leaders: A cross cultural comparison. International Journal of Cross Cultural Management, 8(2), 171-210.

Wood, G. (2008). Gender Stereotypical Attitudes: Past, Present and Future Influences on Women's Career Advancement, Equal Opportunities International, vol. 27, no. 7, pp. 613-628

Yukongdi, V. and Rowley C. (2009). The Changing Face of Women Managers in Asia: Opportunities \& Challenges, Routledge, London, pp. 1-18. 